\title{
Butyl acrylate/4-acryloyloxy benzophenone copolymers as photoreactive UV-crosslinkable pressure-sensitive adhesives
}

\author{
Zbigniew Czech, Agnieszka Butwin \\ West Pomeranian University of Technology, Szczecin, Department of Chemical Organic Technology, K. Pulaskiego 10, \\ 70-322 Szczecin, Poland, e-mail: psa_czech.wp.pl
}

\begin{abstract}
It has previously been shown that copolymers of butyl acrylate with 4-acryloyloxy benzophenone can be used as pressure-sensitive adhesives (PSAs). This paper presents the synthesis and application of a solvent-borne polymer system for the preparation of photoreactive UV-crosslinkable acrylic pressure-sensitive adhesives. Butyl acrylate/benzophenone copolymers with molecular mass in the range 180000 to 480000 Dalton were prepared by carrying out free-radical solution polymerization. These copolymers were found to be tacky but in some cases to possess insufficient cohesive strength after UV-crosslinking to be useful as PSAs. The other copolymers resulted in materials with the balance of cohesive and adhesive characteristics required of good PSAs. Some of the parameters affecting the pressure-sensitive adhesive properties of the copolymers are the concentration of 4-acryloyloxy benzophenone, the molecular mass of the polymeric components, the UVreactivity, and properties such as tack, peel adhesion, and cohesion.
\end{abstract}

Keywords: butyl acrylate, 4-acryloyloxy benzophenone, acrylic copolymers, pressure-sensitive adhesives (PSAs), UV-crosslinking, tack, peel adhesion, cohesion.

\section{INTRODUCTION}

Conventional solvent-borne acrylic pressure-sensitive adhesives (PSAs) are generally copolymers of $\mathrm{C}_{4}-\mathrm{C}_{8}$ alkyl acrylates and polar monomers, such as acrylic acid or hydroxyacrylates. Modifying monomers such as methyl or ethyl acrylate and vinyl acetate can also be incorporated into these copolymers. The optimum cohesive and adhesive properties of the copolymers can be attained with the appropriate balance of its molecular mass (usually very high), the appropriate polarity, and glass transition temperatures ranging from -25 to $-70^{\circ} \mathrm{C}$. Acrylic PSAs are generally applied onto the desired substrates as solventborne or water-borne coatings and subsequently dried. However, on account of solvent and energy costs, time consumption in the drying process, and constraints imposed by environmental pollution regulations, solvent-free pressure-sensitive adhesives play a dominant role.

Solvent-borne acrylic pressure-sensitive adhesives are synthesized in organic solvents as viscoelastic polymers with permanent tack (initial adhesion) and two properties in balance, those of adhesion (peel adhesion) and cohesion (shear strength) ${ }^{1}$. In the long history of technology, pressure-sensitive adhesives (PSAs) and self-adhesive ar- ticles as we know them are fairly recent developments. The history of PSAs has been described by Villa ${ }^{2}$. The diverse crosslinking methods for acrylic PSAs have been discussed in ${ }^{3}$. Ultraviolet-crosslinked solvent-borne acrylic PSAs are one-component systems that have been described $\mathrm{in}^{4-7}$. Photo-induced crosslinking of PSAs is a rapidly expanding technology that has created new properties and improved the quality of chemical bonding. This crosslinking process and the new class of UV-crosslinkable acrylic PSAs have opened up interesting applications in the production of self-adhesive tape, labels, protective films, sign and marking films, masking tape, and dental and medical materials.

The crosslinking mechanism of UV-photoreactive PSA acrylics containing 2-ethylhexyl acrylate and 4-acryloyloxy benzophenone has been thoroughly investigated and is presented schematically in Fig. $1^{8}$.

The behavior of any pressure-sensitive adhesive can be described in terms of three fundamental and interconnected physical properties: tack, peel adhesion, and cohesion?.

Tack is not an exactly defined physical characteristic, but can be defined in terms of the separation energy.<smiles>CCCCCC(CC(C)(C)C)C(=O)OC</smiles><smiles>CC(=O)Oc1ccc(C(=O)c2ccccc2)cc1</smiles><smiles>CCCCOC(=O)CC(CC)(CCCC)C(c1ccccc1)c1ccc(OC(C)=O)cc1</smiles>

Figure 1. UV-crosslinking of acrylic PSAs containing 4-acryloyloxy benzophenone as the internal photoinitiator 
Table 1. Important properties of the UV-crosslinkable $\left(\bar{M}_{w}, \eta\right)$ and UV-crosslinked (tack, peel adhesion, cohesion) acrylic PSAs

\begin{tabular}{|c|c|c|c|c|c|}
\hline 4-acryloyloxy benzophenone [wt.-\%] & $\begin{array}{l}\bar{M}_{w} \\
\text { [Dalton] }\end{array}$ & $\begin{array}{c}\eta \\
{[\mathrm{mPa} ? \mathrm{~s}]}\end{array}$ & $\begin{array}{c}\text { Tack } \\
{[\mathrm{N}]}\end{array}$ & $\begin{array}{l}\text { Peel adhesion } \\
{[\mathrm{N}]}\end{array}$ & $\begin{array}{c}\text { Cohesion }\left(20^{\circ} \mathrm{C}\right) \\
{[\mathrm{N}]}\end{array}$ \\
\hline without & 180000 & 724 & 40.0 & $28.0 \mathrm{cf}$ & 5 \\
\hline 0.1 & 180000 & 731 & 38.5 & $27.6 \mathrm{cf}$ & 5 \\
\hline 0.3 & 183000 & 998 & 37.5 & $27.0 \mathrm{cf}$ & 8 \\
\hline 0.5 & 188000 & 1100 & 36.0 & $25.6 \mathrm{cf}$ & 12 \\
\hline 0.7 & 205000 & 1314 & 34.6 & $24.5 \mathrm{cf}$ & 14 \\
\hline 1.0 & 229000 & 1512 & 30.2 & 19.8 & 26 \\
\hline 1.5 & 287000 & 1800 & 26.8 & 14.7 & 36 \\
\hline 2.0 & 362000 & 2380 & 19.5 & 10.1 & 70 \\
\hline 2.5 & 419000 & 3100 & 12.0 & 8.6 & 95 \\
\hline 3.0 & 480000 & 4330 & 7.5 & 6.6 & 120 \\
\hline
\end{tabular}

cf-cohesion failure

Nevertheless, tack is still widely characterized by how well a self-adhesive sticks to a finger following only slight pressure and short dwell time.

Peel adhesion is the force required to remove a PSAcoated material from a specified test surface.

Cohesion is a real measure of the internal structural resistance of the polymer. Generally, the mechanical and physical (tack, peel adhesion) properties of acrylic PSAs are dependent on its cohesion.

\section{EXPERIMENTAL}

\section{Materials}

The following experiments were conducted to study the influence of varying the concentration of 4-acryloyloxy benzophenone on the properties of synthesized acrylic PSAs, such as viscosity, molecular mass, tack, peel adhesion, and cohesion. The investigated PSAs were synthesized with 0.1 to $3.0 \mathrm{wt}$.\% of 4-acryloyloxy benzophenone and butyl acrylate by carrying out polymerizations in typical organic solvents such as ethyl acetate and acetone in the ratio $80: 20$ with $0.1 \mathrm{wt} . \%$ of the thermal radical initiator AIBN. The polymer content during the polymerization was approximately $50 \mathrm{wt} . \%$. Butyl acrylate, ethyl acetate, acetone, and AIBN are available from BASF (Germany). The unsaturated photoinitiator 4-acryloyloxy benzophenone was purchased from ChemCycle (Germany).

The photoreactive acrylic PSAs were directly coated with $60 \mathrm{~g} / \mathrm{m}^{2}$ dry polymer on a $36 \mu \mathrm{m}$ polyester foil and crosslinked after drying for $10^{\prime}$ at $105^{\circ} \mathrm{C}$ with a UV lamp of type U 350-M-I-DL (from IST) with a UV dose of 900 $\mathrm{mJ} / \mathrm{cm}^{2}$ for various crosslinking times.

\section{Measurements}

The molecular mass studies were performed in tetrahydrofuran with a gel chromatography LaChrom system: an RI Detector L-7490 and a LaChrom UV Detector L-7400 from Merck-Hitachi, equipped with a PLgel $10^{6} \AA$ column from Hewlett-Packard.

The viscosities of the solvent-borne copolymers were determined on a Brookfield Synchro-Lectric Viscometer Model RVT with Thermosel attachment, using spindle \# 27 at $2.5 \mathrm{rpm}$.

The UV-exposure was measured with an integrating radiometer Dynachem ${ }^{\mathrm{TM}}$ Model 500, available from Dynachem Corporation, 2631 Michelle Drive, Tustin, CA 92680.
The performances of the pressure-sensitive adhesive acrylics were characterized according to A.F.E.R.A. (Association des Fabricants Europeens de Rubans AutoAdhesifs) procedures. Administrative address: 60, rue Auber-94408 Vitry Sur Seine Cedex, France. These three main properties were determined by standard A.F.E.R.A. 4015 (tack), 4001 (peel adhesion), and 4012 (cohesion).

\section{RESULTS AND DISCUSSION}

It has previously been shown that copolymers of butyl acrylate with 4-acryloyloxy benzophenone contain a small number of photoreactive groups and exhibit good adhesive performance.

The butyl acrylate-4-acryloyloxy benzophenone copolymers were prepared by carrying out the solution polymerization of the monomers in the presence of AIBN, and were found to have GPC polystyrene equivalent peak molecular weights $\left(\bar{M}_{w}\right)$ in the range 180000 to 480000 Dalton. These copolymers are clear, tacky, and cohesively weak viscous fluids. The data of Table 1 illustrate the effects of varying the 4-acryloyloxy benzophenone content on the molecular mass, viscosity, tack, peel adhesion, and cohesion of the PSA acrylics after UV-crosslinking with a UV dose of $900 \mathrm{~mJ} / \mathrm{cm}^{2} \mathrm{UV}$ for $60 \mathrm{~s}$.

The results in Table 1 are also presented in Figures 2 to 6 . It can be inferred from these results that increasing the concentration of the unsaturated photoinitiator 4 ?acryloyloxy benzophenone results in increases in the molecular mass (Fig. 2) and the viscosity (Fig. 3) of the synthesized UV-crosslinkable solvent-borne acrylic pressure-sensitive adhesives (PSAs).

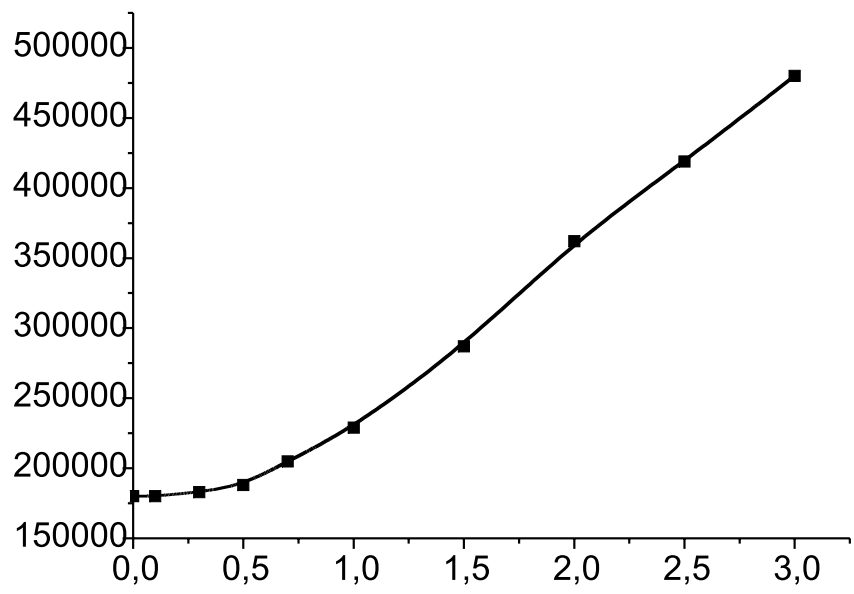

Figure 2. Dependence of $\bar{M}_{w}$ of the acrylic PSAs on the photoinitiator concentration 


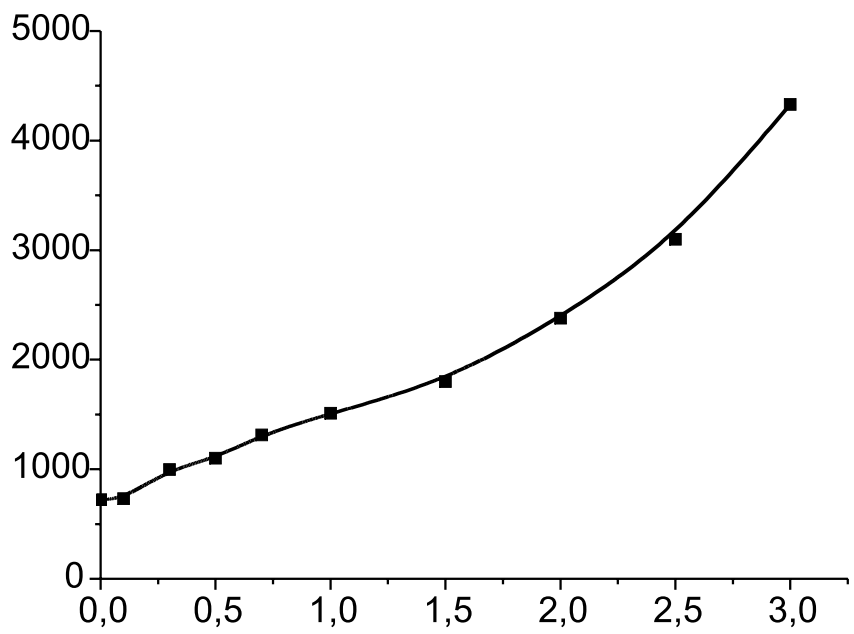

Figure 3. Effects of the photoinitiator content on the acrylic PSA viscosity

The effects of varying the concentration of 4-acryloyloxy benzophenone (internal photoinitiator) on the main PSA properties, such as tack, peel adhesion, and cohesion after a crosslinking time of $60 \mathrm{~s}$ are shown in Figures 4 to 6 .

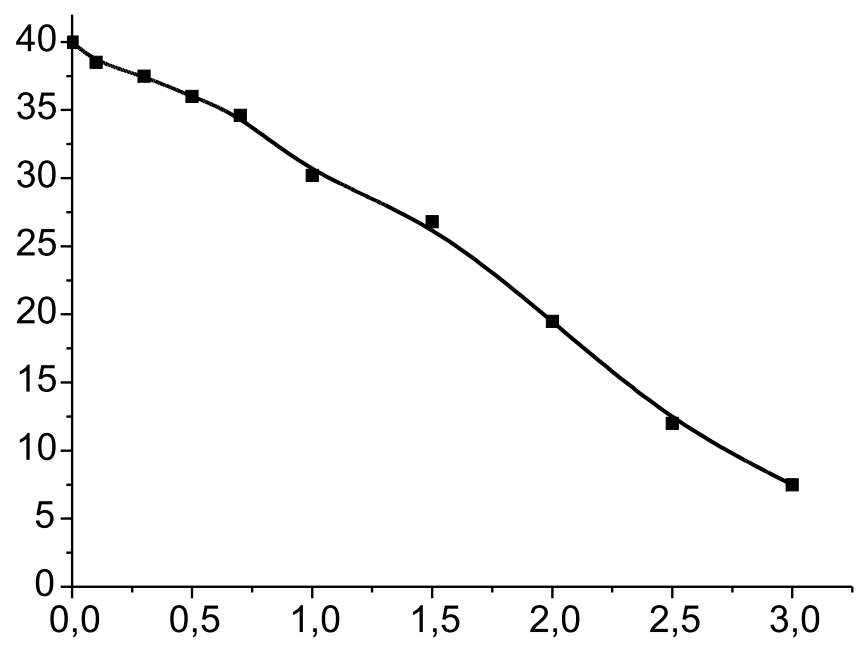

Figure 4. Influence of photoinitiator content on the acrylic PSA tack

Increases in the photoinitiator concentration result in decreases in the tack of the photoreactive solvent-borne acrylic PSAs. For concentrations of 4-acryloyloxy benzophenone between 1.0 to $3.0 \mathrm{wt}$.\%, the tack decreases rapidly. This phenomenon is typical of crosslinked adhesives.

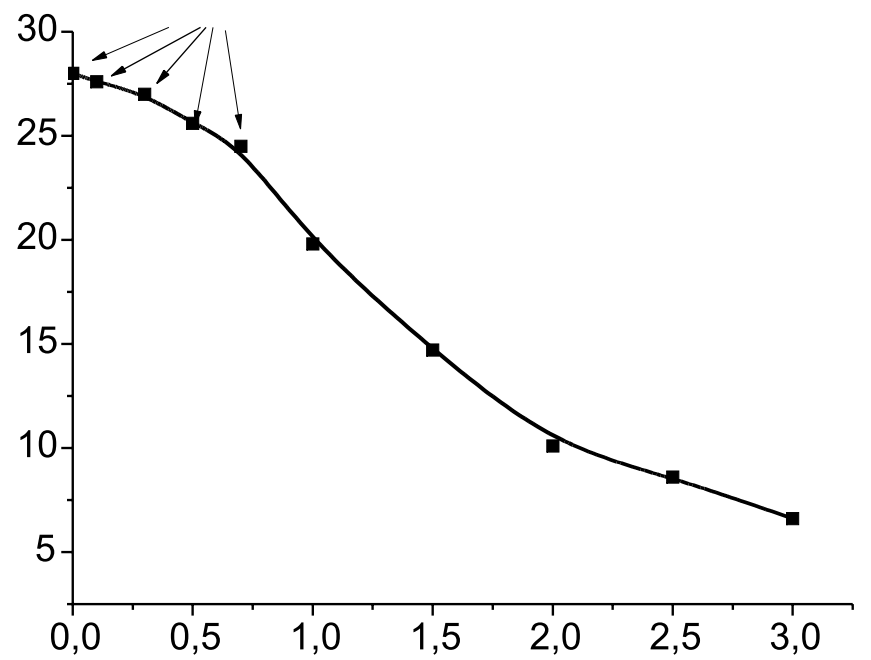

Figure 5. Influence of photoinitiator content on PSA peel adhesion
The highest value of peel adhesion without cohesive failure (cf) was obtained when between 0.7 to $1.0 \mathrm{wt} . \%$ of 4-acryloyloxy benzophenone was used. Concentrations of photoinitiator under $0.8 \mathrm{wt} \%$ resulted in the highest adhesive performance, but also in cohesion failure. These results indicate insufficient cohesion of these acrylic PSAs, and mean they are unacceptable for technological use.

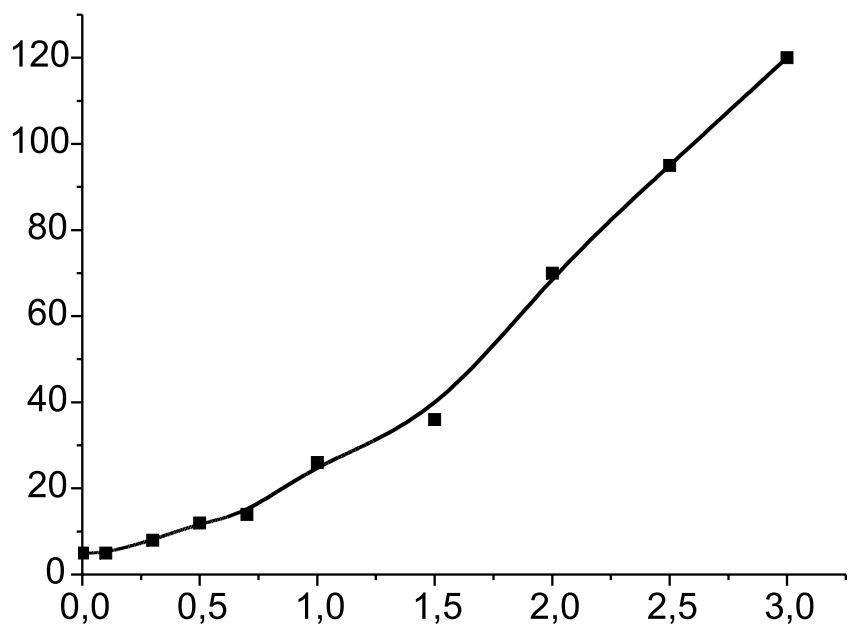

Figure 6. Influence of the photoinitiator content on the PSA shear strength

Increases in the concentration of 4-acryloyloxy benzophenone in the synthesis of the UV-crosslinkable PSA acrylics result in increases in their cohesion. Very high cohesion values of the magnitude of $120 \mathrm{~N}$ were obtained for $3.0 \mathrm{wt} . \%$ 4-acryloyloxy benzophenone in the acrylic copolymer chain. With 1.0 and 1.5 wt.\% unsaturated photoinitiator, acceptable cohesion levels of 30 and $40 \mathrm{~N}$ were achieved.

The performance characteristics of UV-crosslinkable acrylic PSAs are a result of UV-crosslinking, measured as UV-crosslinking time, which occurs when the PSA-coated films are exposed to UV radiation. Figure 7 shows the effects of varying the crosslinking time on the tack, adhesion, and cohesion of the PSAs for a constant 4-acryloyloxy benzophenone concentration (approximately $1.5 \mathrm{wt} . \%$ ).

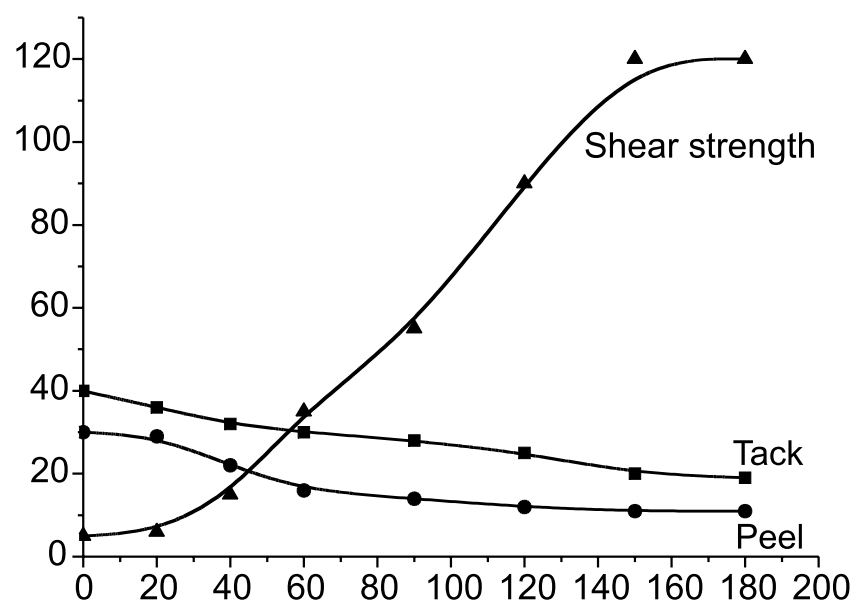

Figure 7. Influence of UV-crosslinking time on tack, peel adhesion, and cohesion

In general, the use of $1.5 \mathrm{wt} . \%$ unsaturated photoinitiator 4-acryloyloxy benzophenone in the acrylic PSA copolymers resulted in the best balance of tack, peel adhesion, 
and shear strength for UV-cross linking times between 60 and $180 \mathrm{~s}$. The optimum tack, peel adhesion, and cohesion values of the UV-crosslinked acrylic PSAs with photoinitiator 4-acryloyloxy benzophenone incorporated into the polymer chain were obtained for a crosslinking time of approximately $90 \mathrm{~s}$.

\section{CONCLUSIONS}

UV-crosslinkable acrylic PSAs offer a good alternative to other crosslinked solvent-borne adhesives.

From our evaluation of the experiments discussed in this publication, it can be concluded that:

- The remarkable performances of the UV-crosslinked solvent-borne acrylic pressure-sensitive adhesives based on butyl acrylate were achieved by incorporating 4acryloyloxy benzophenone into the polymer backbone during polymerization.

- Increasing the concentration of the copolymerizable 4-acryloyloxy benzophenone increases the viscosity and molecular mass of the synthesized solvent-borne acrylic PSAs.

- The best results for the important properties of pressure-sensitive adhesives, namely tack, peel adhesion, and shear strength, were obtained for concentrations of 4acryloyloxy benzophenone of 1.0 and $1.5 \mathrm{wt} . \%$.

- For UV-crosslinking times between 60 and $90 \mathrm{~s}$, the performance of the acrylic PSAs containing 4-acryloyloxy benzophenone reaches a very high level.

- Generally, the properties after UV crosslinking of the synthesized UV-crosslinkable acrylic PSAs containing 4acryloyloxy benzophenone are excellent, in particular their shear strength.

\section{LITERATURE CITED}

1. Benedek, I. (2006). Developments in Pressure-Sensitive Products. CRC Taylor \& Francis, New York.

2. Benedek, I. (2000) Pressure-Sensitive Formulation. VSP, Utrecht.

3. Czech, Z. (1999). Crosslinking of pressure-sensitive adhesives based on acrylic. Ed. Technical University of Szczecin.

4. Auchter, G. (1993). UV-crosslinking of acrylic pressuresensitive adhesives. Adhäsion 1 - 2, 14 - 17.

5. Czech, Z. (2000). Einsatz von Excimerlasern in der Klebstoffchemie. Kautschuk Gummi Kunstoffe 1 - 2, 59 - 65.

6. Czech, Z, Blum, W. \& Herrmann, F. (1993). patent WO 94/14853, Verfahren zur Vernetzung von Haftklebern durch Einsatz von Lasern.

7. Czech, Z. \& Malec, A., (2006) Ultraviolet and thermal initiated crosslinking of solvent-free acrylic PSA, Polish Journal of Chemical Technology 2, $5-8$.

8. Milker, R. \& Czech, Z. (2003). Removable and repositionable pressure-sensitive adhesive products, Stick $3^{\text {rd }}$ European Congress on Adhesive and Sealant Raw Materials, Nürnberg, Germany, 23 - 36.

9. Wabro, K., Milker, R. \& Krüger, G. (1994). Haftklebstoffe und Haftklebebänder. Astorplast, Altdorf, Germany. 